\title{
Pattern of otitis media in young children and adolescents with traditional uvulectomy in Kano, Nigeria
}

\author{
Abdulrazak Ajiya \\ Department of Otorhinolaryngology, Aminu Kano Teaching Hospital/Bayero Uuniversity Kano, Nigeria
}

\begin{abstract}
Traditional uvulectomy is not an uncommon practice in Nigeria and most part of sub-Saharan Africa. Its practice is well documented in these countries. Traditional uvulectomy and otitis media are both prevalent in Nigeria. However, there is a dearth of studies on a causal relationship between the two in the Nigerian subpopulation. This study aims to assess the pattern of otitis media among young children and adolescents who had traditional uvulectomy. This study was a prospective, descriptive, cross-sectional study conducted on all consecutive eligible consenting patients aged 5- to 18-years seen in the ear, nose and throat clinic of Aminu Kano Teaching Hospital with amputated uvula detected during routine examination were recruited. A standard tool was developed to obtain data from the patients. Thereafter otoscopy was done for all the patients. A total of 400 patients were recruited into the study, $246(61.5 \%)$ were male and $154(38.5 \%)$ female. The mean (standard deviation) of age was 12.4 (3.8) years. The commonest indication for traditional uvulectomy among the patients was as ritual [356 (89\%)] with the least been speech disorder and failure to thrive [3 (76\%)] each. Most $(60 \%)$ had no symptoms suggestive of otitis media over the years. However, most (263 and 259 in the right and left ear respectively) participants had dull tympanic membrane on otoscopy. Majority (280) had their uvulectomy in the neonatal period, and post uvulectomy complications were low $(17 \%)$. Symptoms of otitis media are not a common finding in patients with traditionally amputated uvulae.
\end{abstract}

\author{
Correspondence: Abdulrazak Ajiya, Department of \\ Otorhinolaryngology, Akth/Bayero University Kano, Kano State, \\ Nigeria. \\ E-mail: ajiyaabdulrazak@yahoo.com \\ Key words: Uvulectomy, otitis media, otoscopy, Nigeria. \\ Conflict of interest: the author declares no potential conflict of interest. \\ Funding: none. \\ Received for publication: 24 July 2019. \\ Revision received: 9 November 2019. \\ Accepted for publication: 10 November 2019. \\ This work is licensed under a Creative Commons Attribution \\ NonCommercial 4.0 License (CC BY-NC 4.0). \\ (C) Copyright: the Author(s), 2019 \\ Licensee PAGEPress, Italy \\ Annals of African Medical Research 2019; 2:83 \\ doi:10.4081/aamr.2019.83
}

\section{Introduction}

Uvulectomy is described as the surgical removal of the uvula. Also known as staphylectomy or kionectomy, Traditional uvulectomy is a common practice among traditional healers in Nigeria and most parts of the sub-Saharan Africa. ${ }^{1-3}$ It is a procedure that has been practiced in various places and at various times through history. This traditional African surgical practice is well documented in Kenya, Sierra Leóne, Tanzania, Ethiopia, and Nigeria., ${ }^{45}$

Otitis media is described as an inflammatory disease of the middle ear cleft. ${ }^{6}$ It is divided into: acute, chronic, and otitis media with effusion. Otitis media (OM) is a global middle ear disease with health-economic burden, especially in Africa and other developing nations where the disease prevalence could be as high as $11 \%$ with severe economic implications. ${ }^{7,8}$ Traditional uvulectomy in Africa has been an age-long practice and the literature is replete with studies on this practice. ${ }^{9-11}$

Traditional uvulectomy and otitis media are both prevalent in Nigeria; with previous studies reporting $32 \%$ and $11 \%$ respectively. ${ }^{1,12}$ Traditional uvulectomy is still an on-going practice particularly in Northern Nigeria. ${ }^{1}$ However, there is a dearth of studies on a causal relationship between the two in the Nigerian subpopulation.

It's amongst the most prevalent otolaryngologic diseases in Nigerians. ${ }^{13}$

This study aims to assess the pattern of otitis media among young children and adolescents who had traditional uvulectomy.

\section{Materials and Methods}

This study was a prospective, descriptive, cross-sectional study conducted on all consecutive eligible patients aged 5-18 years found to have amputated uvula during routine ear, nose and throat (ENT) examination at the ENT clinic of Aminu Kano Teaching Hospital. Those with diagnosis of the following were excluded: allergic rhinitis, obstructive adenoid disease, cerebrospinal fluid otorrhea, hemotympanum, middle ear tumour and other disorders that could affect middle ear function. The study was carried out over a 6months period in the year 2014 from the months of April to September. The study was performed in accordance with the declaration of Helsinki.

The minimum sample size was determined using the Fischer's formula. ${ }^{14}$

$\mathrm{N}=$ the desired sample size;

$\mathrm{Z}=$ the standard normal deviation, usually set at 1.96 , which corresponds to the $95 \%$ confidence level;

$\mathrm{P}=$ Best estimate of the population prevalence obtained from literature.

An assumption of $32 \%$ was made by extrapolation from a previous study in Jos, ${ }^{1}$ Nigeria. 
$\mathrm{D}=$ Precision. For the purpose of this study, it was estimated as $5 \%$. Therefore, $\mathrm{N}=\mathrm{Z}^{2} \mathrm{PQ} / \mathrm{D}^{2}$

$$
\mathrm{N}=3.84 \times 0.32 \times 0.77 / 0.0025=378
$$

To allow for attrition, $\mathrm{N}$ was approximated to 400 .

Among the limitations of this study was recall bias of past history of otitis media by patients and inter-observer difference during otoscopy.

A specially designed form was used to record information such as age, sex, tribe and occupation. Afterwards the participant's symptoms and past medical history, including the time of uvulectomy were recorded.

A detailed ENT and general examinations were performed with the participant seated on the chair or held in a confortable position by the parent or guardian. The oral cavity and oropharynx were examined with an appropriate headlight and metal tongue depressor. An otoscopy was done with Welch Allyn otoscope, REF. 11720 to inspect the ear canal and tympanic membrane for normal landmarks, signs of inflammation, drainage, wax build-up or damage to the ear canal. The ear was cleared of debris when found.

Ethical approval was sought and obtained from the ethical review committee of Aminu Kano Teaching Hospital (NHREC/21/08/2008/AKTH/EC/911). An informed consent was also obtained from the patients/guardian and an assent from the participants where applicable before recruitment.

Data obtained was analysed using the Statistical Packages for Social Sciences (SPSS) Version 18. Qualitative data was summarized using frequencies and percentages.

\section{Results}

Four hundred participants were recruited into the study. There were 246 males $(61.5 \%)$ and 154 females $(38.5 \%)$ with $\mathrm{M}$ : F ratio of $3: 2$. The age of the participants ranged from 5 to 18 years with a mean of $12.4 \pm 3.8$ years. The majority $302(75.5 \%)$ of the participants with amputated uvula were aged between 10 and 18 years, followed by individuals in the age group 5 to 9 years 98 (24.5\%). Table 1 shows the general characteristics of the study population.

Table 1. General characteristics of the patients.

\begin{tabular}{lcc} 
& Number of patients & Percentages \\
Age group (years) & & \\
5-9 & 98 & 24.5 \\
$10-14$ & 103 & 25.8 \\
$\quad 15-18$ & 199 & 49.7 \\
Sex & & 6 \\
$\quad$ Male & 256 & 1.5 \\
$\quad$ Female & 154 & 38.5 \\
\hline
\end{tabular}

$\mathrm{M}: \mathrm{F}$ ratio of 3:2; age range $=5-18$ years; mean $\pm \mathrm{SD}=12.4 \pm 3.8$ years.

Table 2. Distribution of indications for uvulectomy.

\begin{tabular}{lcc}
\multicolumn{1}{c}{ Indications } & Frequency & Percentage \\
Ritual & 356 & 89.0 \\
Infection & 10 & 2.50 \\
\hline Feeding problems & 25 & 6.25 \\
Failure to thrive & 3 & 0.75 \\
\hline Speech disorders & 3 & 0.75 \\
Others & 3 & 0.75 \\
\hline
\end{tabular}

The most common reason for traditional uvulectomy as reported by the parents and/or guardians of the participants were as traditional rituals for new-borns $356(89 \%)$, followed by feeding problems during infancy $25(6.25 \%)$. Table 2 shows indications for traditional uvulectomy in the study population.

Majority of the patients with amputated uvula had no history suggestive of otitis media from the time of traditional uvulectomy to the time they were interviewed $240(60 \%)$, while $88(22 \%)$ had history of otalgia. Figure 1 depicts the distribution of associated symptoms among the participants in the study group.

Majority of the respondents reported no complication following the procedure $332(83 \%)$, but up to $40(10 \%)$ had significant bleeding following traditional uvulectomy. Figure 2 shows the distribution of complications following traditional uvulectomy among the respondents.

Otoscopic examination findings among the participants with amputated uvula showed that the majority had dull tympanic membrane (263 and 259) followed by those with normal appearing tympanic membrane ( 85 and 84 ) in both the right and left ears. Figure 3 shows the pattern of otoscopic findings among patients with tra-

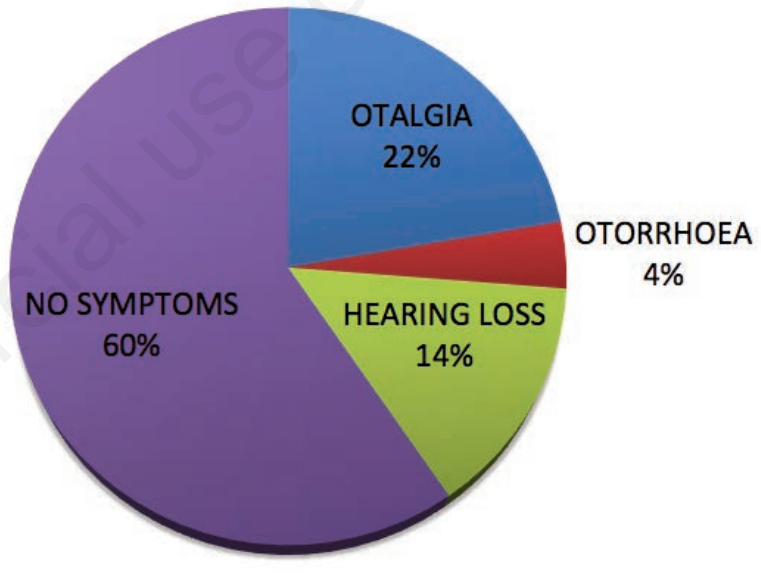

Figure 1. Distribution of associated symptoms in patients with amputated uvula.

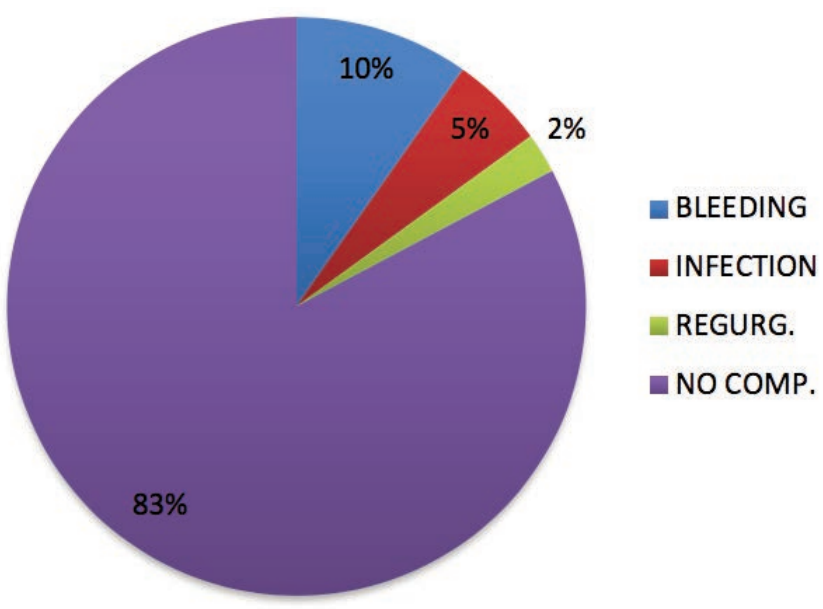

Figure 2. Distribution of complications following traditional uvulectomy. 
ditional amputated uvula.

Majority of the respondents with amputated uvula had the traditional uvulectomy while they were neonates $280(70 \%)$, and up to $108(27 \%)$ had it before the age of 1 year. Figure 4 shows the timing of traditional uvulectomy among the participants.

Pearson chi-squared test showed a strong statistical association between the reason for uvulectomy and later occurrence of otitis media among the patients (P-value less than 0.001). Table 3 shows the association between reason for uvulectomy and occurrence of otitis media.

There was also a statistically significant correlation between post-uvulectomy complication and occurrence of otitis media among the patients (P-value 0.024). Table 4 shows the association between post-uvulectomy complication and occurrence of otitis media.

\section{Discussion}

Traditional uvulectomy is still being widely practised in some African nations including Nigeria. Among the Hausas in Northern Nigeria and Niger, uvulectomy is considered as just that part of the traditional naming ceremony. $3,9,11$

Adolescents in this study were found to be more than young children. Similarly; a study in Jos, North central Nigeria, ${ }^{1}$ revealed the majority of their subjects with traditionally amputated uvulae were in their second decade of life $(44.8 \%)$. This could mean that traditional uvulectomy is a decreasing practise among urban dwellers, which formed the majority of the participants in the study. This study showed that the majority of the participants with traditionally amputated uvulae were males. This agrees with the findings from similar studies in the Northern part Nigeria. ${ }^{1,15}$ Cultural and religious reasons could restrain women from going out of their homes thus restricting the number of those that visit hospitals. In addition, women are exposed to other traditional surgical practises like genital mutilation, which might be considered a more important ritual in the community than uvulectomy.

Many related studies reported traditional uvulectomy to be commonly done during childhood. $1,3,15$ The finding of this study is not in the contrary. This is because traditional uvulectomy is done as part of the traditional naming ceremony in the Northern parts of

Table 3. Association between reason for uvulectomy and occurrence of otitis media.

\begin{tabular}{lccc} 
Otitis media & $\begin{array}{c}\text { Symptoms } \\
\text { present }\end{array}$ & $\begin{array}{c}\text { Symptoms } \\
\text { absent }\end{array}$ & Total \\
Ritual uvulectomy & 118 & 238 & 356 \\
Non-ritual uvulectomy & 42 & 2 & 44 \\
\hline Total & 160 & 240 & 400 \\
\hline
\end{tabular}

P-value $<0.001$ (statistically significant association).

Table 4. Association between of post-uvulectomy complication and occurrence of otitis media.

\begin{tabular}{lccc} 
Complications & No complication & Complication & Total \\
Symptom present & 125 & 35 & 160 \\
Symptom absent & 207 & 33 & 240 \\
\hline Total & 332 & 68 & 400 \\
\hline
\end{tabular}

P-value $=0.024$ (statistically significant association).
Nigeria and Niger. Ritual practise is the commonest reason given for traditional uvulectomy in this study. This is comparable to the findings of related studies in Northern Nigeria and Niger republic. ${ }^{1,3,15}$ This further affirms culture and not health reasons behind the practise.

Acute haemorrhage was the commonest complication reported by the parents and/or guardians of participants with traditionally amputated uvulae in this study. It was twice more common than infection. Along the same line, another study in Jos, Nigeria reported up to $17.6 \%$ of the respondents to have had significant bleeding following traditional uvulectomy. ${ }^{1}$ However, the incidence of complication following traditional uvulectomy in this study was low as up to $332(83 \%)$ respondents reported no complication. This is in contrast to reports from another study in Jigawa, North-western Nigeria that reported complication as high as $88.8 \% .{ }^{15}$ This could be due to recall bias of events by respondents or better technique
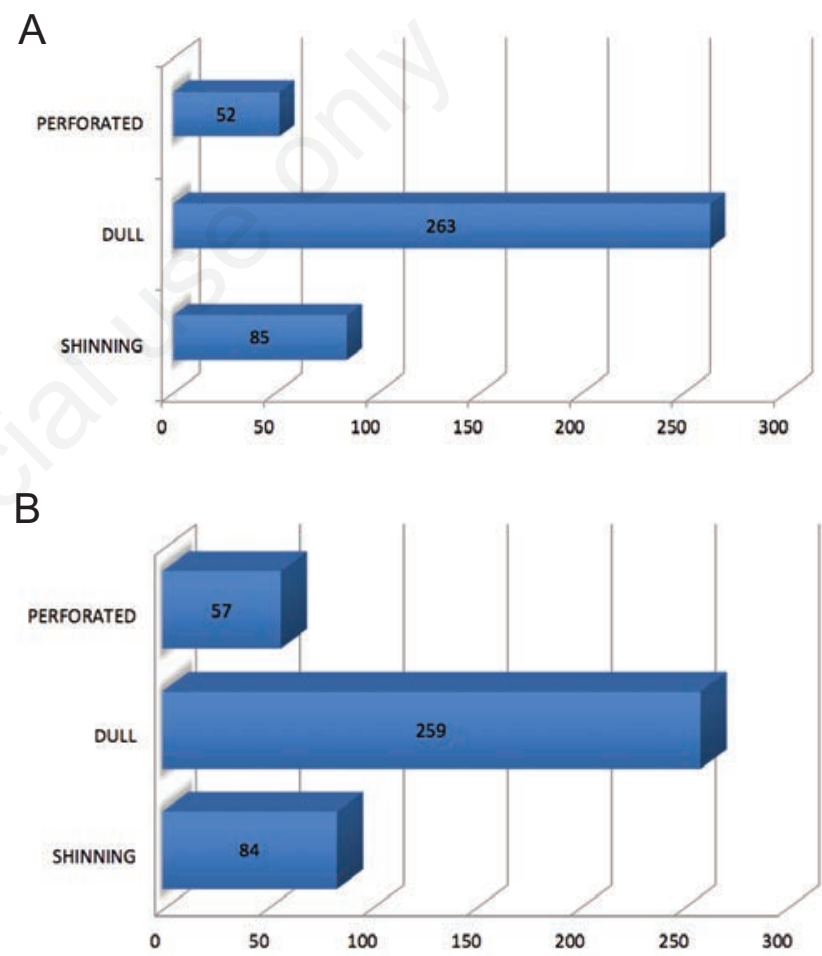

Figure 3. Pattern of otoscopic findings in (A) and (B) ear among patients with amputated uvulae.

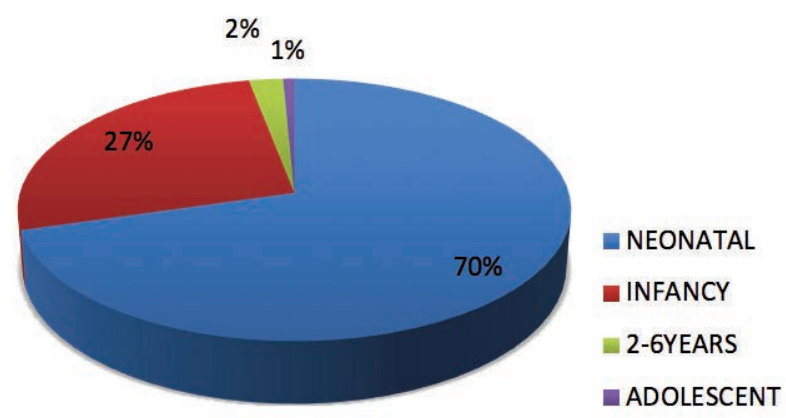

Figure 4. Time of uvulectomy among the participants. 
of the procedure.

This study revealed only $40 \%$ of the respondents reporting symptoms of otitis media with the majority having no middle ear symptoms. Cleft palate and traditional uvulectomy are both thought to predispose to middle ear disease. However, studies on cleft palate patients variously reported otitis media in the majority contrary to the findings in this study amongst patients with amputated uvula. ${ }^{16-18}$

This study revealed associations between indication for uvulectomy and complications of uvulectomy with occurrence of otitis media. This could be explained by the possibility that the barber might decide to remove more than usual for treatment of the prevailing disease, subsequently leading to occurrence of complications and worsened functions of the tubal muscles.

\section{Conclusions}

Symptoms of otitis media are not a common finding in patients with traditional amputated uvulae. From the findings of this study, it is recommended that the public, especially prospective parents should be enlightened on the possible dangers of traditional uvulectomy.

\section{References}

1. Adoga AA, Nimkur TL. The traditionally amputated uvula amongst Nigerians: Still an ongoing practice. ISRN Otolaryngology 2011;2011:704924.

2. Ijaduola GT. Uvulectomy in Nigeria. J Laryngol Otol 1981;95:1127-33.

3. Prual A, Gamatie Y, Djakounda M, Higuet D. Traditional uvulectomy in Niger: a public health problem? Soc Sci Med 1994;39:1077-82.

4. Manni JJ. Uvulectomy, a traditional surgical procedure in Tanzania. Ann Trop Med Parasitol 1984;78:49-53.

5. Lowe KR. Severe anaemia following uvulectomy in Kenya.
Military Med 2004;169:712.

6. Oh HM. Upper Respiratory Tract Infections: Otitis Media, Sinusitis and Pharyngitis. Singapore Med J 1995;36:428-31.

7. Alberta Medical Association. Guideline for the diagnosis and treatment of acute otitis media in children. Alberta Clinical Practice Guidelines Program 2000.

8. World Health Organization. Prevention of hearing impairment from chronic otitis media. Report of a WHO/CIBA foundationworkshop.1998. Available from: https://apps.who.int/iris/handle/10665/63870

9. Hunter L. Uvulectomy the making of a ritual. South Afr Med J 1995;85:901-2.

10. Katz SS. Uvulectomy: A common ethno-surgical procedure in Africa. Med Anthropol Q 1989;3:62-69.

11. Elinor A. Clinical pearl: Uvulectomy.1996. Available from: http://ethnomed.org/clinical/mother-and-infant-care/pearl1. Assessed June 2012.

12. Ibekwe TS, Nwaorgu OG. Classification and management challenges of otitis media in a resource-poor country. Niger J Clin Pract 2011;14:262-9.

13. Eziyi JAE, Amusa YB, Akinpelu OV. Prevalence of Otolaryngological diseases in Nigerians. East Central Afr J Surg 2010;15:85-9.

14. Araoye MO. Research Methodology with statistics for health and social sciences. Nathadex, Ilorin Nigeria. 2004:115-24.

15. Ajibade BL, Okunlade JO, Kolade OA. Harmful cultural practices: parents perceived effects of traditional uvulectomy on the under-five children in Jigawa state, Nigeria. IOSR J Dent Med Sci 2013;9:8-13.

16. D'Mello J, Kumar S. Audiological findings in cleft palate patients attending speech camp. Indian $\mathrm{J}$ Med Res 2007; 125:777-82.

17. Tuncbilek G, Ozgur F, Belgin E. Audiologic and tympanometric findings in children with cleft palate and lip. Cleft Palate Craniofac J 2003;4:304-9.

18. Handzic-cuk J, Cuk V, Gluhinic M, et al. Tympanometric findings in cleft palate patients: influence of age and cleft type. J Laryngol Otol 2001;115:91-6. 